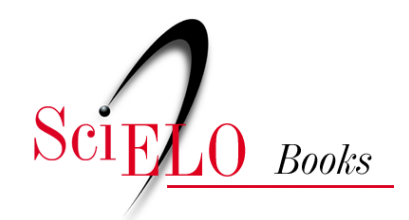

EDUFU

\title{
Teatro e comunidade
}

\author{
Marcia Pompeo Nogueira
}

SciELO Books / SciELO Livros / SciELO Libros

NOGUEIRA, M.P. Teatro e comunidade. In: FLORENTINO, A., and TELLES, N., eds. Cartografias do ensino do teatro [online]. Uberlândia: EDUFU, 2008, pp. 173-183. ISBN 978-85-7078-518-3. https://doi.org/10.7476/9788570785183.0018.

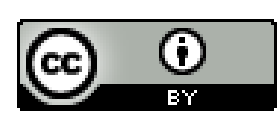

All the contents of this work, except where otherwise noted, is licensed under a Creative Commons Attribution 4.0 International license.

Todo o conteúdo deste trabalho, exceto quando houver ressalva, é publicado sob a licença Creative Commons Atribição $\underline{4.0}$.

Todo el contenido de esta obra, excepto donde se indique lo contrario, está bajo licencia de la licencia $\underline{\text { Creative Commons }}$ Reconocimento 4.0. 


\section{TEATRo E COMUnidAde}

\section{Marcia Pompeo Nogueira}

Teatro na Comunidade é um fenômeno que se manifesta de diversas formas, assumindo diferentes nomes em diferentes países: teatro popular, teatro para o desenvolvimento, teatro radical do povo, teatro para a libertação, etc. Assim como nomes diferentes podem significar a mesma coisa, nomes iguais podem significar coisas diferentes. Nos Estados Unidos, por exemplo, o Teatro Comunitário é o nome dado para o que chamamos no Brasil de Teatro Amador. Trata-se de uma modalidade teatral difícil de definir, já que adquire diferentes formatos, ligada a diferentes instituições e finalidades. Baz Kershaw propõe a seguinte definição:

Sempre que o ponto de partida [de uma prática teatral] for a natureza de seu público e sua comunidade. Que a estética de suas performances for talhada pela cultura da comunidade de sua audiência. Neste sentido estas práticas podem ser categorizadas enquanto Teatro na Comunidade ${ }^{1}$.

O autor chama atenção para a natureza política deste tipo de teatro direcionado a platéias "cuidadosamente selecionadas". Mas antes de aprofundarmos nosso entendimento desta modalidade teatral, precisamos ter claro o que vem a ser comunidade. Ainda se pode falar de comunidade nos dias de hoje?

\section{O conceito de comunidade}

Quando falamos de comunidade a primeira imagem que geralmente se faz é de uma comunidade rural, pequena, estável, isolada geograficamente.

Pessoas interagiam umas com as outras enquanto seres sociais "totais" informados por um amplo conhecimento de cada um, cujos relacionamentos são freqüentemente formados por ligações de afinidade e consangüinidade ${ }^{3}$.

\footnotetext{
${ }^{1}$ KERSHAW, Baz The politics of performance: radical theatre as social intervention. Londes: Routledge, 1992. p. 5.

2 KERSHAW, 1992, p. 5.

${ }^{3}$ COHEN, Anthony. The symbolic construction of community. Londres: Routledge, 1985. p. 25.
} 
Esta perspectiva seria completamente distinta da comunidade urbana, caracterizada pela multiplicidade de contextos, no qual as pessoas:

Vivem em um [lugar] e trabalham em outro, viajam para ainda outros, indo talvez para outro lugar no seu tempo de lazer. Esta pluralidade de contextos é reproduzida estruturalmente na própria ecologia da cidade, dividida em zonas, claramente distinguível pela população e função. Os vestígios da comunidade seriam somente encontrados no nível das vizinhanças ${ }^{4}$.

Diante desta fragmentação e diferenças internas, pode-se até concluir que a comunidade não poderia sobreviver à industrialização e urbanização. Entretanto, Cohen chama atenção de que a unicidade aparente das comunidades rurais são simplificações, escondem diversidades, hierarquias, baseadas em diferentes bases: idade, posição social etc. O que daria a aparência de unicidade seria, segundo este autor, a aceitação de símbolos comuns sobre o significado da comunidade. A aceitação dos mesmos símbolos identifica uma comunidade, mesmo quando cada indivíduo o interpreta a sua maneira. Comunidade implicaria, portanto, em semelhanças e diferenças.

Qualquer comunidade - rural ou urbana - ou formas de associações, teriam a função estrutural e ideológica, segundo Raymond Willians, de mediar os indivíduos e a sociedade mais ampla 5 .

Para Kershaw, toda comunidade é parecida no que diz respeito às diferenças internas que abriga e ao papel de mediação que assume entre o indivíduo e a sociedade. Ele cita dois tipos de comunidade:

'Comunidade de local' é criada por uma rede de relacionamentos formados por interações face a face, numa área delimitada geograficamente.

'Comunidade de interesse', como a frase sugere, são formadas por uma rede de associações que são predominantemente caracterizadas por seu comprometimento em relação a um interesse comum. Quer dizer que estas comunidades podem não estar delimitadas por uma área geográfica particular. Quer dizer também que comunidades de interesse tendem a ser explicitas ideologicamente, de forma a que mesmo se seus membros venham de áreas geográficas diferentes, eles podem de forma relativamente fácil reconhecer sua identidade comum ${ }^{6}$.

No primeiro sentido, acredita-se que pessoas que vivem e/ou trabalham numa mesma região possuem determinadas vivências e problemas comuns, enquanto o segundo indica que algumas pessoas comungam idéias, se identificam por um olhar preconceituoso com que são vistas, ou sofrem uma mesma exclusão, como por exemplo: mulheres, homossexuais, negros, meninos de rua, domésticas, entre outros. Boal chama esses grupos de "temáticos - formados por participantes que, por alguma razão, ou idéia, algum forte objetivo se uniram [...]”7.

\footnotetext{
${ }^{4}$ SPENGLER apud COHEN, 1985, p. 25 -26.

5 WILLIAMS, Raymond. The long revolution. Harmondsworth: Pelican, 1965. p. 95.

${ }^{6}$ KERSHAW, 1992, p. 31.

7 BOAL, Augusto. Teatro legislativo. Rio de Janeiro: Civilização Brasileira, 1996b. p. 70.
} 
Desta forma, assumimos a conceituação de Anthony Cohen em relação ao entendimento do que é comunidade:

Comunidade não se define apenas em termos de localidade. [...] É a entidade à qual as pessoas pertencem, maior que as relações de parentesco, mas mais imediata do que a abstração a que chamamos de "sociedade". É a arena onde as pessoas adquirem suas experiências mais fundamentais e substanciais da vida social, fora dos limites do lar ${ }^{8}$.

\section{Origens do teatro na comunidade}

A origem deste teatro pode ser associada à própria origem do teatro, quando não havia separação entre quem faz e quem assiste o teatro. Ou como diz Boal, à festa popular:

"Teatro" era o povo cantando livremente ao ar livre: o povo era o criador e o destinatário do espetáculo teatral, que se podia então chamar "canto ditirâmbico". Era uma festa em que podiam todos livremente participar?.

Neste sentido, são consideradas raízes desse teatro as tradições populares pré-coloniais e greco-romanas. Já as raízes mais imediatas dessa modalidade podem ser associadas a movimentos mais recentes de reaproximação do teatro de seu público.

De forma bastante resumida ${ }^{10}$, pode-se dizer que o ponto de partida desta reaproximação do teatro com a comunidade foi o seu movimento de disseminação, cujo objetivo inicial era ampliar seu acesso para além do público burguês, que podia pagar os ingressos. Como, por exemplo ${ }^{11}$, o Movimento Socialista, especialmente durante a segunda internacional (1890 - 1914), entendia-se como mensageiro da cultura, com a função de levar educação e conhecimento para as massas. Baseado inicialmente em dramaturgia alheia aos interesses específicos da classe trabalhadora, envolvendo uma gama de peças que iam do melodrama ao naturalismo, o teatro era ainda limitado ao uso de estilos tradicionais. A proposta era oferecer alta cultura, evitando qualquer tentativa de instrumentalização.

Arte podia levar uma mensagem social, mas era senso comum, entre seus ideólogos e críticos [do movimento socialista], que ela serviria melhor ao movimento se fosse verdadeira para si mesma, absorvendo idéias emancipatórias, mas expressas, em primeiro lugar, artisticamente ${ }^{12}$.

\footnotetext{
8 COHEN, 1985, p. 15.

9 BOAL, Augusto. Teatro do oprimido: e outras poéticas políticas. Rio de Janeiro: Civilização Brasileira, 1983. p. 14.

${ }^{10}$ Para mais detalhes, ver NOGUEIRA, Marcia Pompeo. Towards a poetically correct theatre for development: a dialogical approach. 2002. 224 p. Tese (Doutorado) - Universidade de Exeter, 2002. Não publicada.

${ }^{11}$ Existem outros exemplos de práticas que integram este movimento de disseminação do teatro. Ver, entre outros, GARCIA, Silvana. Teatro de militância. São Paulo: Perspectiva, 1990. 208 p.

${ }^{12}$ SAMUEL, Raphael; MACCOLL, Ewan; COSGROVE, Stuart. Theatre of the left, 1880-

1935: workers' theatre movements in Britain and America. London: Routledge \& Kegan Paul, 1985. p. XVII.
} 
Contribuiu para este movimento de disseminação do teatro o novo entendimento do papel da classe trabalhadora na sociedade. Segundo a filosofia marxista, o proletariado passou a ser visto como classe revolucionária, que poderia guiar a sociedade na luta pela superação do capitalismo. Atingir este público passou a ser um objetivo de várias iniciativas.

A origem deste percurso também está associada a espetáculos teatrais que, a partir do início do século XX, passaram a assumir uma perspectiva política de transformação da realidade, e enfrentaram os limites da dependência econômica do teatro profissional. Montagens com objetivos políticos explícitos, apresentadas em teatros de regiões centrais, evidenciavam, na verdade, uma contradição: o conteúdo político, objetivo deste teatro, era apresentado apenas para um público burguês que podia pagar o ingresso. Esta contradição impulsionou dois movimentos: de um lado diversas iniciativas de atingir um novo público se efetivam através de turnês para os lugares mais remotos do globo; de outro experiências em que o público se transforma em ator ganham espaço ${ }^{13}$.

O percurso do Teatro de Arena, no Brasil, inclui um exemplo de questionamento da contradição vivida por grupos que tinham uma prática de teatro político e atuavam em casas de espetáculo situadas em regiões centrais. Como expresso por Vianinha:

O Teatro de Arena trazia dentro de sua estrutura um estrangulamento que aparecia na medida mesmo em que se cumprisse sua tarefa. O Arena era porta-voz das massas populares num teatro de cento e cinqüenta lugares ${ }^{14}$.

Essa contradição mobilizou o Arena e muitos outros grupos, em diversos países, para buscar um novo público, para sair das casas de espetáculo, ganhar a estrada, e levar o teatro para o povo.

Finalmente, indentificamos como raízes imediatas do Tearo na Comunidade as rupturas formais das convenções teatrais, fruto de diversos movimentos de vanguarda artística, que revolucionaram as práticas teatrais no século XX: o cenário havia deixado de ser necessário, e até mesmo o palco; teatro poderia ser feito em qualquer lugar. O fazer teatral passou a ser visto, por alguns artistas, como acessível a todos, os métodos de trabalho se democratizaram e processos de criação coletiva se multiplicaram.

\section{Formas do teatro na comunidade}

Segundo Van Erven, os diferentes estilos do Teatro na Comunidade se unem por "sua ênfase em histórias pessoais e locais (em vez de peças prontas) que são trabalhadas inicialmente através de improvisações e ganham forma teatral coletivamente" 15 . Seus materiais e formas sempre emergem diretamente (se não exclusivamente) da comunidade, cujos interesses se tenta expressar.

\footnotetext{
13 O próprio Teatro Didático de Bertold Brecht, onde não havia necessidade de expectadores, era fruto do enfrentamento dessa contradição.

${ }_{14}$ VIANINHA apud BERLINK, Manoel. O centro popular de cultura da UNE. Campinas: Papirus, 1984. p. 20.

${ }_{15}$ VAN ERVEN, Eugene. Community theatre: global perspectives. Londres: Routledge, 2001. p. 2.
} 
No percurso assumido pela prática de Teatro na Comunidade, identificamos basicamente três modelos, frutos de uma evolução histórica. Pode-se dizer que esses modelos partem de práticas decididas de cima para baixo, para práticas cujo objetivo e métodos são decididos pelas pessoas que participam dos projetos teatrais. Entretanto, este percurso não é o único, pois todas essas etapas podem ser encontradas ainda hoje. O que existe de comum entre todos esses modelos é que "são representados fora dos holofotes metropolitanos"16. Os três modelos seriam:

\section{Teatro para comunidades}

Este modelo inclui o teatro feito por artistas para comunidades periféricas, desconhecendo de antemão sua realidade. Caracteriza-se por ser uma abordagem "de cima pra baixo", um teatro de mensagem. Como nos diz Boal:

Usávamos nossa arte para dizer verdades, para ensinar soluções: ensinávamos os camponeses a lutarem por suas terras, porém nós éramos gente da cidade grande; ensinávamos aos negros a lutarem contra o preconceito racial, mas éramos quase todos alvíssimos; ensinávamos às mulheres a lutarem contra os seus opressores. Quais? Nós mesmos, pois éramos feministas-homens, quase todos. Valia a intenção ${ }^{17}$.

\section{Teatro com Comunidades}

Este modelo, em geral, parte de uma crítica do modelo anterior em termos da fragilidade dos resultados atingidos. Aqui, o trabalho teatral parte de uma investigação de uma determinada comunidade para a criação de um espetáculo. Tanto a linguagem, o conteúdo - assuntos específicos que se quer questionar - ou a forma - manifestações populares típicas - são incorporados ao espetáculo.

A idéia de vinculação a uma comunidade específica estaria ligada à ampliação da eficácia política do trabalho.

Os anos de contato com públicos específicos e comunidades específicas ensinaram uma importante lição aos trabalhadores do teatro radical: cada tipo de comunidade, cada tipo de grupo requer uma abordagem sob medida - de forma a se tornar eficaz culturalmente e, talvez social e politicamente ${ }^{18}$.

\section{Teatro por Comunidades}

O terceiro modelo tem grande influência de Augusto Boal. Inclui as próprias pessoas da comunidade no processo de criação teatral. Partindo de uma perspectiva crítica ao teatro de mensagem, Boal enfrenta um outro tipo de contradição do teatro com objetivos políticos. Esta proposta é relatada por Boal no formato de uma história sobre a reação de um camponês nordestino, das ligas camponesas. Ela expressa os fundamentos da evolução do teatro de mensagem em relação ao teatro participativo.

\footnotetext{
${ }^{16}$ VAN ERVEN, 2001, p. 243.

17 BOAL, Augusto. O arco-íris do desejo: método Boal de teatro e terapia. Rio de Janeiro: Civilização Brasileira, 1996a. p. 17-18.

${ }_{18}$ KERSHAW, 1992, p. 165.
} 
A história narrada por Boal começa quando, ao final de um espetáculo, os atores emocionados diziam: "Derramemos nosso sangue!". Após o espetáculo, o Sr. Virgílio veio conversar com os atores, emocionado, quase chorando: “- É uma beleza ver vocês, gente moça da cidade, que pensa igualzinho que nem a gente. A gente também acha isso, que tem que dar o sangue pela terra"19

Boal revela a alegria dos atores por sentirem que a mensagem tinha atingido o público, mas Virgílio, um homem descrito como alto e forte, continuou:

- E já que vocês pensam igualzinho que nem a gente, vamos fazer assim: primeiro a gente almoça (era meio dia), depois vamos todos juntos, vocês com estes fuzis de vocês, e nós com os nossos, vamos desalojar os jagunços do coronel que invadiram a roça de um companheiro nosso $[\ldots]^{20}$.

Assustados, responderam, com muito cuidado, que os fuzis eram adereços, que não eram armas de verdade. Mas Sr. Virgílio continuou:

— Se os fuzis são de mentira, pode jogar fora, mas vocês são gente de verdade, eu vi vocês cantando pra derramar o sangue, sou testemunha. "Vocês são de verdade, então venham com a gente assim mesmo porque nós temos fuzis para todo mundo"21.

Boal diz que "o medo fez-se pânico"22. E, com muito custo, explicou que eles eram artistas e que nem sabiam atirar. Então Sr. Virgílio concluiu: “-Então aquele sangue que vocês acham que a gente deve derramar é o nosso, não o de vocês...?”23.

Esta história marca a origem do Teatro do Fórum. Boal cita Che Guevara para explicitar a aprendizagem que esta vivência lhes proporcionou: "Ser solidário significa correr os mesmos riscos" 24 . Marca a crítica ao teatro de mensagem e uma abertura para uma nova perspectiva de teatro na comunidade. Em vez de fazer peças dizendo o que os outros devem fazer, passou-se a perguntar ao povo o conteúdo do teatro, ou dar ao povo os meios de produção teatral. Transformar o povo de espectador em ator.

Esta evolução proposta por Boal influenciou muitos trabalhos de teatro e comunidade no mundo todo. Ganhou forma um novo Teatro na Comunidade, cuja função seria fortalecer a comunidade. $O$ Teatro passou a ser a arena privilegiada para se refletir sobre questões de identidade de comunidades específicas, contribuindo para o aprofundamento das relações entre os diferentes segmentos da comunidade que podem, através da improvisação, do jogo teatral, explicitar suas semelhanças e diferenças. O teatro seria, neste sentido, porta-voz de assuntos locais, o que poderia contribuir para expressão de vozes silenciosas ou silenciadas da comunidade. Como dizem alguns autores, o teatro feito pela comunidade contribuiria para a "contínua regeneração do espírito de comunidade" 25 .

19 BOAL, 1996a, p. 18.

${ }^{20}$ BOAL, 1996a, p. 18.

${ }^{21}$ BOAL, 1996a, p. 18.

${ }^{22}$ BOAL, 1996a, p. 18.

${ }^{23}$ BOAL, 1996a, p. 19.

${ }^{24}$ BOAL, 1996a, p. 19.

${ }^{25}$ KERSHAW, 1992, p. 60. Referência de Baz Kershaw aos resultados de uma conferência sobre 


\section{Um exemplo de teatro comunidade africano}

A evolução de um teatro preocupado em trazer mensagens para o povo, para um teatro feito pelas pessoas teve também, na história do Kamiriithu, no Quênia, um modelo.

Ngugi wa Thiong'o e outros artistas do Departamento de Literatura da Universidade de Nairobi, que já assumiam uma postura política crítica através de suas peças teatrais nacionalistas radicais e antiimperialistas. Além da perspectiva crítica do conteúdo dessas peças, buscavam também quebrar os limites de um teatro formal e, ao mesmo tempo, buscavam ampliar o acesso a suas peças.

Ngugi wa Thiong'o foi procurado, em 1976, por uma moradora do Kamiriithu, vilarejo próximo a sua casa, para apoiar as atividades de um centro comunitário que estava passando por dificuldades. Como resposta a esta solicitação e pela insistência da senhora, ele resolveu contribuir. O resultado foi um projeto fantástico. Trabalhadores, camponeses, professores, desempregados e empresários construíram, com suas próprias mãos, um teatro ao ar livre de 2.000 lugares, que integrava o centro cultural, o qual passou a abrigar um curso de alfabetização e teatro.

A peça Ngaabika Ndeenda (Me Caso Quando Quiser), escrita por Ngugi wa Thiong'o e Ngugi wa Miiri, para a comunidade do Kamiriithu, bebeu nas fontes da luta por terra e liberdade, parte das lutas pela independência do Quênia, na qual muitos dos trabalhadores e camponeses da comunidade participaram, seja de forma ativa ou passiva. "Muitos viram suas casas serem queimadas; suas filhas estupradas pelos Ingleses; suas terras roubadas; seus parentes mortos"26.

A peça celebrava esta história e ao mesmo tempo mostrava como a independência, pela qual muitos quenianos morreram, estava sendo expropriada pelo poder neocolonial, ainda dominado pelos interesses britânicos. A peça também retratava as condições sociais contemporâneas dos trabalhadores, tanto nas multinacionais como nas plantações ${ }^{27}$.

A escolha da língua falada na peça foi crucial. Muitas peças revolucionárias da época eram representadas em inglês - língua duramente imposta pelos colonizadores e ensinada nas escolas - mas os camponeses não podiam entendê-la bem. A escolha do Gikuyu, língua local, ampliou a participação. Esta foi a primeira vez que Ngugi wa Thiong'o escreveu em Gikuyu. Educado em inglês, teve que aprender novamente sua língua mãe.

A experiência do Kamiriithu representou um enorme processo de aprendizagem para os professores universitários. Eles aprenderam com os atores e com a platéia, que contribuíram com elementos de suas experiências de vida, e até em relação às idéias gerais apresentadas na peça, que foi re-escrita durante o processo de criação:

O processo, particularmente para Ngugi wa Miiri, Kimani Gecau, e para mim foi de aprendizagem contínua. Aprendemos nossa história. Aprendemos o que acontece

Teatro na Comunidade, em 1983, no Dartington College, Inglaterra.

${ }^{26}$ THIONG'O, Ngugi Wa. Decolonising the mind: the politics of language in African literature. London: James Currey; Nairobi: EAEP; Portsmouth: Heinemann, 1986. p. 45.

27 THIONG'O, 1986, p. 44. 
nas fábricas. Aprendemos nossa língua, já que os camponeses eram essencialmente os guardiões da língua por anos de uso. Aprendemos também uma nova forma de Teatro Africano ${ }^{28}$.

A aprendizagem da forma veio do reconhecimento de como as músicas e as danças eram centrais para a vida das pessoas no Quênia, presente nas celebrações especiais como nas conversas cotidianas.

Em Ngaahika Ndeenda tentamos incorporar músicas e danças, como parte da estrutura e do movimento dos atores. A música vinha do que estava acontecendo em cena e liderava a cena que se seguia. A música e a dança viravam a continuidade da conversa e da ação ${ }^{29}$.

A montagem durou nove meses: de janeiro a setembro de 1977. Os ensaios aconteciam aos finais de semana e eram assistidos por cerca de 300 pessoas da comunidade, que contribuíam para o processo discutindo a forma como sua história vivida era apresentada, sugerindo detalhes sobre as danças e músicas, ajudando a reconstruir os rituais, encontrando a linguagem correta para personagens específicos em relação a sua idade e ocupação. Debates acalorados aconteceram durante todo o processo em relação à forma e ao conteúdo da peça. Mesmo o processo de representação era parte do processo educacional compartilhado e das contribuições coletivas:

A prática do Kamiriithu foi parte de um processo educacional, enquanto um processo de desmistificação do conhecimento e portanto da realidade. As pessoas podiam ver como os atores evoluíam do momento em que mal conseguiam mover suas pernas e dizer suas falas para o momento em que conseguiam conversar e se movimentar no palco como se tivessem nascido lá dizendo estas falas. Algumas pessoas eram recrutadas para o elenco depois de uma intervenção em que mostravam como este ou aquele personagem deveria ser mostrado. A platéia os aplaudia para que continuassem fazendo o papel. Perfeição foi assim mostrada como sendo um processo, um processo histórico social, mas era mesmo assim admirada. Pelo contrário se identificavam ainda mais com esta perfeição porque era um produto deles e de sua contribuição. Era uma elevação deles mesmos enquanto uma comunidade ${ }^{30}$.

A peça foi um sucesso enorme. Veio gente de todos os lugares para assistir. Isto assustou o governo, que agiu violentamente. Em 16 de novembro de 1977, o governo do Quênia baniu qualquer outra apresentação do espetáculo. Ngugi wa Thiong’o foi preso em 31 de dezembro de 1977 e passou todo o ano de 1978 em prisão de segurança máxima.

O espaço aberto que ajudou a comunidade queniana a reconectar-se com suas raízes rompidas representou uma ameaça maior para o governo do que as peças políticas feitas anteriormente por Ngugi wa Thiong'o, apesar das últimas terem um

${ }^{28}$ THIONG'O, 1986, p. 45.

29 THIONG'O, 1986, p. 45.

30 THIONG'O, 1986, p. 57. 
conteúdo revolucionário mais explícito. Lendo, por exemplo, a peça de Ngugi wa Thiongo's, The Trial of Dedan Kimathi (O Julgamento de Dedan Kimathi), seu conteúdo revolucionário é bem mais evidente do que em Vou me Casar Quando Quiser. Mesmo assim, o efeito político foi muito mais ameaçador para o governo, e provocou uma pressão política muito maior. A relevância política deste teatro na comunidade ia além de seu conteúdo, que incluía a participação da comunidade no processo criativo. A participação da comunidade em torno de seus próprios interesses representou um novo tipo de desenvolvimento.

Outras experiências em muitos outros países africanos guiaram-se nesta direção de uma arena dramática da comunidade, inspiradas pelo modelo do Kamiriithu, bem como nas idéias de Augusto Boal e Paulo Freire. O método evoluiu de acordo com a experiência em outros contextos, especialmente durante os anos 1980.

\section{Aspectos estéticos e éticos do teatro na comunidade}

Os processos de criação nesta área envolvem freqüentemente a interação de artistas classe média com pessoas de comunidades periféricas. Em termos metodológicos, esta interação exige o enfrentamento de muitas questões: como evitar uma relação de invasão cultural? Como criar uma relação dialógica? Como pode se dar a interação de culturas diferentes? Qual o papel do facilitador? Paulo Freire ${ }^{31}$ fornece as bases de muitos trabalhos que enfrentam este tipo de desafio. Seu método fundado no diálogo, no respeito pelo diferente, exige períodos preparatórios de conhecimento mútuo, em que ambos, comunidade e facilitadores, pesquisam a comunidade na busca de temas significativos que podem estar na base de processos teatrais conjuntos.

Freqüentemente, em trabalhos de Teatro na Comunidade, os objetivos são definidos em termos dos conteúdos:

O trabalho de teatro na comunidade é de criar uma dialética entre o estado presente e as possibilidades futuras de uma comunidade particular, moderada pelo conhecimento sobre e a identificação com estas comunidades ${ }^{32}$.

Mesmo não sendo o principal foco explícito de muitos trabalhos de Teatro na Comunidade, a questão estética também está presente. Como dissemos anteriormente, a produção de teatro, nesta área, é talhada pela cultura da comunidade. Trata-se de uma estética com padrões particulares que não pode ser julgada segundo parâmetros estranhos a ela:

O status de toda arte legítima e da alta cultura é confirmado por uma elite burguesa que promove seu próprio gosto social e culturalmente determinado enquanto naturalmente superior e relega a arte comunitária para uma categoria decididamente inferior de expressão cultural ${ }^{33}$.

${ }^{31}$ FREIRE, Paulo. Pedagogia do oprimido. Rio de Janeiro: Paz e Terra, 1977. 204 p

${ }^{32}$ KERSHAW, 1978 apud KERSHAW, 1992, p. 61.

${ }^{33}$ HAWKINS apud VAN ERVEN, 2001, p. 252. 
A superação desta perspectiva pode contribuir para enfocar um novo entendimento da estética do Teatro na Comunidade, de modo a superar a forma como esta área artística vem sendo marginalizada: “[...] não são somente os participantes considerados 'periféricos' [da periferia], teatro na comunidade enquanto uma forma artística também o é" ${ }^{34}$. Esta marginalização, que se reflete na falta de publicações a respeito, na falta de debate sobre seus resultados e da especificidade de sua estética, precisa ser superada para que possamos nos informar mais sobre as práticas existentes, para que estas práticas possam ser aprimoradas e que revertam em mais benefícios para as comunidades.

$\overline{{ }^{4} \text { VAN ERVEN, 2001, p. } 2 .}$ 


\section{REFERÊNCIAS}

BERLINK, Manoel. O centro popular de cultura da UNE. Campinas: Papirus, 1984.

BOAL, Augusto. O arco-íris do desejo: método Boal de teatro e terapia. Rio de Janeiro: Civilização Brasileira, 1996a.

BOAL, Augusto. Teatro do oprimido: e outras poéticas políticas. Rio de Janeiro: Civilização Brasileira, 1983.

BOAL, Augusto. Teatro legislativo. Rio de Janeiro: Civilização Brasileira, $1996 \mathrm{~b}$.

COHEN, Anthony. The symbolic construction of community. Londres: Routledge, 1985.

FREIRE, Paulo. Pedagogia do oprimido. Rio de Janeiro: Paz e Terra, 1977.

GARCIA, Silvana. Teatro de militância. São Paulo: Perspectiva, 1990.

KERSHAW, Baz The politics of performance: radical theatre as social intervention. Londes: Routledge, 1992.

NOGUEIRA, Marcia Pompeo. Towards a poetically correct theatre for development: a dialogical approach. 2002. 224 p. Tese (Doutorado) - Universidade de Exeter, 2002. Não publicada.

SAMUEL, Raphael; MACCOLL, Ewan; COSGROVE, Stuart. Theatre of the left, 18801935: workers' theatre movements in Britain and America. London: Routledge \& Kegan Paul, 1985.

THIONG'O, Ngugi Wa. Decolonising the mind: the politics of language in African literature. London: James Currey; Nairobi: EAEP; Portsmouth: Heinemann, 1986.

VAN ERVEN, Eugene. Community theatre: global perspectives. Londres: Routledge, 2001.

WILLIAMS, Raymond. The long revolution. Harmondsworth: Pelican, 1965. 